\title{
MÉTODOS ALTERNATIVOS DE SOLUÇÃO DE CONFLITOS E O NOVO PARADIGMA DA JUSTIÇA RESTAURATIVA
}

\section{ALTERNATIVE METHODS OF CONFLICT SOLUTION AND THE NEW PARADIGM OF RESTORATIVE JUSTICE}

José Vicente

Advogado, Mestre em Administração e Doutor em Educação pela Universidade Metodista de Piracicaba. Mestrando em Direito pela Escola Paulista de Direito. Diretor-Geral da

Faculdade Zumbi dos Palmares (FAZP). E-mail: reitoria@zumbidospalmares.edu.br

Vander Ferreira de Andrade

Advogado. Doutor em Direito Público pela Pontifícia Universidade Católica de São Paulo. Coordenador do Curso de Pós-Graduação em Direito Público e do Curso de Graduação em Direito da Faculdade Zumbi dos Palmares (FAZP). E-mail: vander.andrade@fsa.br

Recebido em: 25/05/2017

Aprovado em: 19/10/2017

Doi: $10.5585 /$ rdb.v18i7.681

RESUMO: O presente artigo objetiva promover uma apresentação do modelo identificado como "Justiça Restaurativa", posto em confronto com o sistema formal e tradicional da "Justiça Retributiva". Valendo-se de documentos internacionais e de experiências obtidas no Direito Comparado, bem como diante de incipientes vivências no território nacional, apresenta uma alternativa ao modelo de justiça realizado pelo sistema de instância estatal. Advoga a possibilidade de outras formas de promoção da justiça que não seja exclusivamente por intermédio dos aparelhos e instrumentos públicos. Nesse sentido, confere especial destaque para a adoção do modelo de justiça restaurativa, não olvidando algumas objeções, restrições e vantagens na sua aplicação concreta, como instrumento de alternativo de solução de conflitos. Nessa conformidade, o sistema restaurativo é apresentado sob o formato de uma alternativa ao tradicional modelo retributivo, em especial diante da ineficiência e ineficácia social, e igualmente a partir do reconhecimento de sua insuficiência na tratativa das questões relacionadas com os conflitos de maior envergadura e alcance. O trabalho propõe uma reflexão sobre esse novel sistema de intervenção social, com vistas à busca do reequilíbrio das relações humanas e sob o enfoque da possibilidade de uma reconstrução de um ambiente de harmonia social, no qual se imanta, dentre outros corolários, i relevante papel desempenhado pela reparação dos danos, sempre que possível. Ao final, aponta-se para a viabilidade da adoção das práticas restaurativas, adicionadas ao sistema retributivo, de prejuízo das ainda necessárias medidas presentes no modelo tradicional de retribuição representado simbólica e efetivamente a partir da aplicação da pena.

Palavras-chave: Métodos Alternativos de Solução de Conflitos. Justiça. Sistema Restaurativo. Sistema Retributivo. 
ABSTRACT: The present article aims to promote a presentation of the model identified as "Restorative Justice", in contrast to the formal and traditional system of "Retributive Justice". Using international documents and experiences obtained in Comparative Law, as well as in the face of incipient experiences in the national territory, it presents an alternative to the model of justice carried out by the system of state authority. It advocates the possibility of other forms of promotion of justice that are not exclusively through public instruments and instruments. In this sense, it gives special emphasis to the adoption of the model of restorative justice, not forgetting some objections, restrictions and advantages in its concrete application, as an instrument of alternative conflict resolution. Accordingly, the restorative system is presented in the form of an alternative to the traditional model of retribution, especially in the face of inefficiency and social inefficiency, and also from the recognition of its insufficiency in dealing with issues related to the larger conflicts and scope. The paper proposes a reflection on this novel system of social intervention, with a view to the search for a rebalancing of human relations and under the focus of the possibility of a reconstruction of an environment of social harmony, in which, among other corollaries, Repaired, wherever possible. In the end, the viability of adopting restorative practices, coupled with the retributive system, is suggested to prejudice the still necessary measures present in the traditional model of retribution represented symbolically and effectively from the application of the penalty.

Keywords: Alternative Methods of Conflict Resolution. Justice. Restorative System. Remuneration System.

SUMÁRIO: Introdução. 1. Origem da Justiça Restaurativa. 2. Conceito de Justiça Restaurativa. 3. A Justiça Restaurativa no Brasil. 4. Projetos Pioneiros no Brasil. 5. Justiça Restaurativa no direito comparado. 6. Da Resolução 2002/12 da ONU. 7. Das garantias processuais fundamentais das partes envolvidas no processo restaurativo. 8. Justiça Restaurativa versus Justiça Retributiva. Conclusão. Referências Bibliográficas.

\section{INTRODUÇÃO}

O atual modelo de repressão do delito perpassa pelo tradicional sistema de justiça retributiva. Esse modelo como cediço, se caracteriza por compreender o fenômeno da infração como uma conduta antissocial que demanda uma resposta estatal, tendo como foco a punição do ofensor, punição esta que impõe ser personalizada e individualizada, a partir do emprego das regras rígidas e formalmente estabelecidas, inerentes ao dogmatismo legal.

Nesse mesmo sistema retributivo, verifica-se a prevalência da obrigatoriedade e da indisponibilidade da ação penal, a predominância de sanções plasmadas pelo cerceamento da liberdade, e pela atenção secundária que se devota ao papel da vítima.

Já o modelo restaurativo objetiva propor uma quebra desse paradigma tradicional de sancionamento por meio de instâncias formais, acompanhada de uma proposta de ampliação do raio de extensão do delito, abarcando nesse contexto a vítima, o ambiente comunitário e a pessoa do infrator; não há se falar, nesse viés, em foco concentrado na punição, mas sim, num olhar direcionado para a reparação de danos, numa responsabilidade mais abrangente, na qual a própria sociedade se apresenta como parte integrante.

Há assim no modelo restaurativo uma prevalência do emprego de medidas penais alternativas, bem como o da adoção de instrumentos procedimentais mais flexíveis, bem como caracterizados por uma maior informalidade; quanto à ação penal, esta se declina sob o formato da não obrigatoriedade e o da disponibilidade, sendo que o procedimento prestigia o emprego de ferramentas de conciliação e de mediação; desse modo, o sistema restaurativo projeta como relevante o dever reparatório em face do prejuízo causado, assim como o da aplicação de sanções 
humanizadas e proporcionais à dimensão do dano; nesse diapasão, objetiva atender a vítima com primazia, colocando-a em destacado relevo diante da necessidade de atendimento de suas demandas.

\section{ORIGEM DA JUSTIÇA RESTAURATIVA}

Acredita-se que o termo "Justiça Restaurativa" tenha sido cunhado por Albert Eglash, que em 1977 teria se valido de tal denominação quando da publicação de um artigo científico ${ }^{1}$.

Relativamente aos primórdios do modelo restaurativo, optamos adotar o magistério de Mylène $\mathrm{Jaccoud}^{2}$, a qual discorre que já nas antigas sociedades comunais, privilegiavam-se as práticas de regulamentação social focadas na manutenção da sua coesão. Nestes grupos sociais, a transgressão da norma demandava uma reação voltada para o restabelecimento do equilíbrio que fora rompido, por meio de uma ordem negociada, para se evitar a desestabilização do grupo social. Com a centralização do poder e o surgimento dos estados modernos, houve o afastamento da vítima do processo criminal e as práticas de justiça perderam o sentido de promover a reintegração social. Nesse cenário, as formas de justiça negociada perderam espaço.

Destarte, o advento do sistema restaurativo tem a sua origem numa concepção calcada na necessidade de serem retomadas as práticas de resolução de conflitos tradicionais dos povos comunais, por meio de uma ordem de justiça negociada, na busca de se estabelecer um reequilíbrio das relações afetadas e maior coesão social; destarte, os fatores decisivos para o surgimento do movimento restaurativista foram as manifestações de contestação das instituições repressivas, da descoberta da vítima e de elevação do paradigma comunitário.

$\mathrm{O}$ primeiro originou-se nas universidades norte-americanas e teve como um dos maiores destaques os trabalhos da Escola de Chicago e da criminologia radical. Tal movimento adotou a premissa apregoada por Durkheim no sentido de que o crime não deve ser compreendido como um fato social patológico, mas sim como uma face da provia vida social. O movimento vitimológico apareceu após o término da Segunda Guerra Mundial e gerou o interesse dos estudiosos de se debruçar sobre as demandas próprias e particulares da vítima, demandando um novo olhar para o seu papel dentro do cenário do crime e de sua responsabilização.

Por derradeiro, também apresentou expressiva relevância para o surgimento do modelo restaurativista o movimento que fez a promoção da comunidade, relembrando as sociedades tradicionais valorizando-as como o locus em que os conflitos são em menor número, admitindo melhor administração e, pro via de consequência, maior coesão social.

\section{CONCEITO DE JUSTIÇA RESTAURATIVA}

O modelo proposto pela justiça restaurativa se descortina como um sistema de justiça criminal, não restrito somente a esse campo do direito, tanto assim que diversas práticas restaurativas tem sido adotadas com relativa incidência no ambiente escolar, bem como no campo do direito da infância e da juventude.

Com efeito, a justiça restaurativa que tem como alicerce uma concepção preliminar caracterizada pelo consenso, pela colaboração e pelo diálogo; vale dizer, todos os atores de um ato antissocial, em especial, o ofensor, a vítima, bem como todas as demais pessoas vinculadas pela infração se encontram no processo restaurativo de forma a elaborar conjuntamente

\footnotetext{
1 EGLASH, Albert. "Beyond Restitution: Creative Restitution”. In: Restitution in Criminal Justice”, 1977.

2 JACCOUD, Mylène. Princípios, Tendências e Procedimentos que Cercam a Justiça Restaurativa. In: PINTO, Renato Sócrates Gomes et al. Justiça Restaurativa. Coletânea de Artigos. Brasília: Ministério da Justiça e Programa das Nações Unidas para o Desenvolvimento - PNUD, 2005. p. 163/165.
}

Revista de Direito Brasileira | São Paulo, SP | v. 18 | n. 7 | p. 103 - 113 |Set./Dez. 2017 
alternativas de solução que tenham por desiderato a reparação ou a mitigação dos danos causados pelo ilícito, permitindo ao transgressor sua reintegração social.

Renato Gomes Pinto define a justiça restaurativa como sendo:

"um processo estritamente voluntário, relativamente informal, com a intervenção de mediadores, podendo ser utilizadas técnicas de mediação, conciliação e transação para se alcançar o resultado restaurativo, objetivando a reintegração social da vítima e do infrator".

Por sua vez o Conselho Nacional de Justiça $(\mathrm{CNJ})$ assim define a justiça restaurativa:

“...processo colaborativo voltado para resolução de um conflito caracterizado como crime, que envolve a participação maior do infrator e da vítima. Surgiu no exterior, na cultura anglo-saxã. As primeiras experiências vieram do Canadá e da Nova Zelândia e ganharam relevância em várias partes do mundo. Aqui no Brasil ainda estamos em caráter experimental, mas já está em prática há dez anos. Na prática existem algumas metodologias voltadas para esse processo. A mediação vítima-ofensor consiste basicamente em colocá-los em um mesmo ambiente guardado de segurança jurídica e física, com o objetivo de que se busque ali acordo que implique a resolução de outras dimensões do problema que não apenas a punição, como, por exemplo, a reparação de danos emocionais" $"$.

\section{A JUSTIÇA RESTAURATIVA NO BRASIL}

Verifica-se no Brasil, em especial quando da criação do procedimento jurídico penal que instalou o país os denominados Juizados Especiais Criminais, prenúncios de um modelo restaurativo, agregados ao ordenamento pátrio por meio da lei 9099 de 1995. Obviamente que seu alcance se coloca, nos termos exatos da regra de regência aplicável, estritamente acanhados, em especial pelo fato dos denominados juizados possuírem competência demarcada para o processamento das infrações penais de pequeno potencial ofensivo, assim consideradas todas aquelas cuja pena seja inferior a 2 (dois) anos.

Outro instante em que se verificam extratos aparentes da influencia do sistema restaurativo, pode ser observado quando da análise do sistema que rege a interposição da ação penal privada, onde a não obrigatoriedade, a não oficialidade e a disponibilidade se colocam como diretrizes orientadoras desse tipo especial de ação criminal; igualmente, no corpo do Estatuto do Idoso, incorporado ao ordenamento jurídico brasileiro por meio da lei 10.741/03, podem ser encontrados vestígios da influência da justiça restaurativa, tanto que o procedimento restaurativo previsto para o processamento dos delitos praticados contra pessoas idosas se faz de forma especial quando a pena privativa de liberdade não ultrapassa os 4 (quatro) anos.

Parece-nos relevante frisar, todavia, que o modelo restaurativo vai muito além do procedimento judicial relativo dos juizados especiais para o fim de "resgatar a convivência pacífica no ambiente afetado pelo crime, em especial naquelas situações em que o ofensor e a vítima tem uma convivência próxima", como pontua o juiz Asiel Henrique de Sousa, num estudo preliminar para a implantação de um Projeto Piloto em Brasília, no Núcleo Bandeirante. Em suas reflexões, ainda não publicadas, acrescenta ele que "em delitos envolvendo violência doméstica,

\footnotetext{
${ }^{3}$ SOUSA, Aziel Henrique de. Justiça Restaurativa: O que é e como funciona. Brasília: CNJ, Conselho Nacional de Justiça. 2014.
}

Revista de Direito Brasileira | São Paulo, SP | v. 18 | n. 7 | p. 103 - 113 | Set./Dez. 2017 
relações de vizinhança, no ambiente escolar ou na ofensa à honra, por exemplo, mais importante do que uma punição é a adoção de medidas que impeçam a instauração de um estado de beligerância e a consequente agravação do conflito" .

Em verdade, como aponta Delano Câncio Brandão, os princípios da Justiça restaurativa encontraram solo fértil nos "países que adotam o commom Law, isso porque em tais países o princípio da oportunidade inerente ao sistema de justiça é compatível com o ideal restaurativo" "; nesse sentido, há de ser observado que o Brasil ainda caminha lentamente na direção do ideal restaurativo, não se podendo olvidar a importância de alguns projetos-piloto instalados de forma pioneira em cidades como Porto Alegre, Brasília e São Caetano do Sul e que já começam a gerar frutos, mercê de seus bons resultados e de sua consequente multiplicação em outras comarcas do país.

\section{PROJETOS PIONEIROS NO BRASIL}

Em Porto Alegre, numa parceria entre a Justiça Instantânea (projeto do Tribunal de Justiça do Estado do Rio Grande do Sul), a Fundação de Atendimento Socioeducativo, a Fundação de Assistência Social e Cidadania, a Secretaria Municipal dos Direitos Humanos e Segurança Urbana e a Faculdade de Serviço Social da Pontifícia Universidade Católica do Rio Grande do Sul, aplica-se a justiça restaurativa em casos de jovens reincidentes.

Os casos admitidos em Porto Alegre envolvem a confissão do ato pelo ofensor, a identificação da vítima e o não envolvimento de homicídio, latrocínio, estupro ou conflito familiar.

O processo é dividido em etapas. Primeiramente, faz-se a seleção dos casos; em seguida, encaminham-se para a fase do "Pré-Círculo", em que se explica, às partes, o que é a justiça restaurativa e na qual se constata seu interesse ou não em participar. Após, entra-se na etapa do "Círculo Restaurativo", em que, acompanhados de coordenadores. Após a participação de ambas as partes, chega-se a um acordo/plano.

Esse acordo/plano é redigido pelos coordenadores assinado pelas partes. A partir de então, o ofensor é encaminhado ao Programa de Execução de Medidas Socioeducativas, acompanhado de um técnico que observará o cumprimento do acordo. Outro técnico acompanha as necessidades da vítima. Por fim, ocorre a etapa do "Pós-Círculo", em que se verifica se o acordo foi cumprido pelas partes.

Em São Caetano do Sul, desenvolveu-se um modelo de justiça restaurativa nas escolas estaduais voltado ao público da $4^{\mathrm{a}}$ à $8^{\mathrm{a}}$ série do ensino fundamental, essencialmente adolescentes entre 9 e 16 anos.

Nesse caso, qualquer conflito pode ser encaminhado ao Círculo Restaurativo, e qualquer pessoa pode fazer a indicação - geralmente, quem o faz são as partes ou os professores, que são os coordenadores do projeto. O programa dá ênfase aos casos de bullying que ocorrem no ambiente escolar.

Para que ocorra o Círculo Restaurativo, é necessária concordância das partes. Os casos, depois de concluídos, necessariamente são enviados ao juízo, cuja função é observar os casos concretos. Muitas vezes, os próprios juízes concedem a remissão e nem sequer encaminham os jovens às medidas socioeducativas.

Em Brasília, o programa é construído numa parceria entre o Tribunal de Justiça do Distrito Federal e dos Territórios, o Ministério Público do Distrito Federal e dos Territórios, a

\footnotetext{
${ }^{4}$ GOMES PINTO, Renato Sócrates. Justiça Restaurativa é Possível no Brasil? In: Justiça Restaurativa. Ministério da Justiça, Brasil, 2005.

5 Brandão, Delano Câncio. Justiça Restaurativa no Brasil: Conceito, críticas e vantagens de um modelo alternativo de resolução de conflitos. Revista âmbito Jurídico, 2014.
} 
Defensoria Pública do Distrito Federal, a Secretaria de Estado de Ação Social, a Universidade de Brasília, o Instituto de Direito Internacional e Comparado e a Escola da Magistratura do Distrito Federal, e é dado enfoque aos casos em que os envolvidos possuem um relacionamento que se projete para o futuro ou se prolongue.

O programa é dividido em algumas etapas. Primeiro, faz-se a seleção dos casos e consulta-se ofensor e vítima sobre o interesse em participar do projeto. Nesse momento, explicase o que é a Justiça Restaurativa, e só se prossegue com o programa se as partes anuírem com seu andamento.

Em seguida, realizam-se os Encontros Preparatórios, em que as partes, geralmente amparadas por familiares e amigos, preparam-se emocionalmente para o processo. É nesse momento que se discute o que será dito e como reagir ao relacionamento com a outra parte.

Por fim, chega-se à etapa central do programa, que é o Encontro Restaurativo. Nessa fase, as partes discutem o conflito e elaboram um acordo, que será homologado pelo Juiz e pelo Ministério Público. Após seis meses, as partes se reúnem para verificar o cumprimento do acordo.

\section{JUSTIÇA RESTAURATIVA NO DIREITO COMPARADO}

Interessante estudo objetivando efetuar a comparação entre diversos países que adotaram, ainda que de forma incipiente, o sistema de justiça restaurativa, foi apresentado por Jan Froestad e Clifford Shearing ${ }^{6}$; segundo os estudiosos, no Reino Unido, nos Estados Unidos e na maior parte da Europa, a justiça restaurativa foi associada a formas de mediação entre as vítimas e os infratores. O primeiro programa de reconciliação vítima-infrator foi estabelecido em 1974 em Kitchener, Ontario, pela comunidade Mennonite. O modelo enfatiza a mediação direta e focalizou a cura de ferimentos e a assistência às vítimas, ajudando os infratores a mudar suas vidas e restabelecer relações.

A necessidade de humanizar o sistema de justiça criminal foi uma forte motivação por trás do programa, assim como a ideia de que os programas de justiça restaurativa baseados na igreja são a melhor proteção contra a cooptação do programa. Atualmente, assume-se que existam pelo menos 300 programas em funcionamento nos Estados Unidos e mais de 500 na Europa, que buscam a mediação entre as vítimas e os infratores, normalmente depois da emissão da sentença. Tanto nos Estados Unidos como no Reino Unido, o movimento das vítimas parece ter sido uma raiz importante para a introdução e moldagem dos programas de mediação vítimainfrator.

Na década de 80, os esquemas de mediação ingleses foram criticados fortemente por serem muito orientados ao infrator; assim, o movimento das vítimas ajudou o processo de mediação vítima-infrator a alcançar, pelo menos teoricamente, um equilíbrio entre as necessidades e os interesses das vítimas e dos infratores. Mais de 500 programas de mediação vítima-infrator estão atualmente em funcionamento nos Estados Unidos e no Canadá. A vasta maioria baseia-se na comunidade ou na igreja.

A mediação parece estar imparcialmente distribuída com igualdade pelo processo de justiça criminal. A maioria dos casos são agressões, roubos e crimes juvenis de menor gravidade. Os esquemas de mediação ingleses se baseiam mais na mediação indireta, usando abordagens de "mensageiros" em comparação à inclinação por encontros "cara a cara" entre as vítimas e os infratores nos Estados Unidos.

\footnotetext{
${ }^{6}$ SHEARING, Clifford e Froestad, Jan. Prática da Justiça - O Modelo Zwelethemba de Resolução de Conflitos. In: Justiça Restaurativa. Ministério da Justiça, Brasil, 2005.
} 
Devido às leis de compensação relativamente generosas para vítimas, a restituição financeira tem sido uma preocupação menor na Inglaterra que nos Estados Unidos. A maioria dos esquemas de mediação ingleses funciona na fase de advertência ou após a condenação, mas antes da sentença final. Os esquemas têm sido tipicamente de pequena escala e limitados a uma gama relativamente estreita de crimes de menor gravidade.

Comparados aos programas de reconciliação vítima-infrator, os esquemas de mediação vítima-infrator têm tipicamente tirado a ênfase da reconciliação e enfatizado a cura das vítimas, a responsabilidade dos infratores e a restauração das perdas. A mediação é feita principalmente por voluntários treinados. Muitos esquemas de mediação buscaram, pelo menos teoricamente, recrutar pares de mediadores em que cada qual compartilhe algumas características, como etnia, quer com a vítima ou com o infrator. Os mediadores oriundos de grupos minoritários ainda parecem ser escassos.

Estes modelos enfatizam a responsabilidade do mediador em criar um espaço seguro para a interação entre a vítima e o infrator, a não-obrigatoriedade de acordos e o ideal da intervenção mínima do mediador. Cada vez mais, os atos de mediação parecem ir na direção do que os práticos chamam de "mediação de múltiplas partes", encorajando os partidários a acompanhar as vítimas e os infratores em reuniões.

Na Nova Zelândia, na Austrália e em alguns lugares do Canadá, os desenvolvimentos da justiça restaurativa se relacionaram a uma revivificação de práticas de resolução de conflitos indígenas. Os encontros restaurativos na Nova Zelândia são usados principalmente para infratores que cometeram infrações mais graves e reincidentes. Comparadas à Nova Zelândia e à Austrália, as reuniões na Inglaterra e em Gales parecem ter se desenvolvido de uma base mais ad hoc, fora de uma estrutura estabelecida por lei. Os projetos restaurativos tipicamente funcionam fora do sistema de justiça criminal formal, em posições locais, marginais, e precárias.

\section{DA RESOLUÇÃO 2002/12 DA ONU}

Em 24 de julho de 2012, a Organização das Nações Unidas editou a Resolução 2012, votada em sua $37^{a}$ Sessão Plenária, a qual tem como escopo a adoção de princípios uniformes e básicos para a utilização de programas de justiça restaurativa em matéria criminal.

Assim através desse importante expediente, a ONU reconhece a importância da justiça restaurativa e passa a apresentar algumas definições, assim delineadas:

Programa de Justiça Restaurativa: qualquer programa que use processos restaurativos e objetive atingir resultados restaurativos.

Processo restaurativo: qualquer processo no qual a vítima e o ofensor, e, quando apropriado, quaisquer outros indivíduos ou membros da comunidade afetados por um crime, participam ativamente na resolução das questões oriundas do crime, geralmente com a ajuda de um facilitador. Os processos restaurativos podem incluir a mediação, a conciliação, a reunião familiar ou comunitária (conferencing) e círculos decisórios (sentencing circles).

Resultado restaurativo: acordo construído no processo restaurativo. Destarte, sob o olhar das Nações Unidas, os resultados restaurativos incluem respostas e programas tais como reparação, restituição e serviço comunitário, objetivando atender as necessidades individuais e coletivas e responsabilidades das partes, bem assim promover a reintegração da vítima e do ofensor.

Tais programas incluem as partes, assim consideradas a vítima, o ofensor e quaisquer outros indivíduos ou membros da comunidade afetados por um crime que podem estar envolvidos em um processo restaurativo, bem como aponta para a importância da condução do processo restaurativo por meio de um "facilitador", o qual é definido como sendo uma pessoa 
cujo papel é facilitar, de maneira justa e imparcial, a participação das pessoas afetadas e envolvidas num processo restaurativo.

Relativamente à utilização dos programas de justiça restaurativa, as Nações Unidas recomendam que mesmos devam ser usados em qualquer estágio do sistema de justiça criminal, de acordo com a legislação nacional, todavia, com a cautela de serem empregados somente quando houver prova suficiente de autoria para denunciar o ofensor e com o consentimento livre e voluntário da vítima e do ofensor; para esse fim, a vítima e o ofensor devem poder revogar esse consentimento a qualquer momento, durante o processo e os acordos só poderão ser pactuados voluntariamente, devendo conter somente obrigações razoáveis e proporcionais.

Ainda segundo a Resolução da ONU, a vítima e o ofensor devem normalmente concordar sobre os fatos essenciais do caso sendo isso um dos fundamentos do processo restaurativo. A participação do ofensor não deverá ser usada como prova de admissão de culpa em processo judicial ulterior; as disparidades que impliquem em desequilíbrios, assim como as diferenças culturais entre as partes, devem ser levadas em consideração ao se derivar e conduzir um caso no processo restaurativo.

A segurança das partes deve ser considerada ao se derivar qualquer caso ao processo restaurativo e durante sua condução; assim, quando não for indicado ou possível o processo restaurativo, o caso deve ser encaminhado às autoridades do sistema de justiça criminal para a prestação jurisdicional sem delonga. Em tais casos, deverão ainda assim as autoridades estimular o ofensor a responsabilizar-se frente à vítima e à comunidade e apoiar a reintegração da vítima e do ofensor à comunidade.

No que se refere à operação dos programas restaurativos, a Resolução das Nações Unidas preceitua que os Estados membros devem estudar o estabelecimento de diretrizes e padrões, na legislação, quando necessário, que regulem a adoção de programas de justiça restaurativa. Tais diretrizes e padrões devem observar os princípios básicos estabelecidos no presente instrumento e devem incluir, entre outros, as condições para encaminhamento de casos para os programas de justiça restaurativos, o procedimento posterior ao processo restaurativo, a qualificação, o treinamento e a avaliação dos facilitadores, o gerenciamento dos programas de justiça restaurativa, além da adoção de padrões de competência e códigos de conduta regulamentando a operação dos programas de justiça restaurativa.

\section{DAS GARANTIAS PROCESSUAIS FUNDAMENTAIS DAS PARTES ENVOLVIDAS NO PROCESSO RESTAURATIVO}

As garantias processuais fundamentais que assegurem tratamento justo ao ofensor e à vítima devem ser aplicadas aos programas de justiça restaurativa e particularmente aos processos restaurativos; nesse sentido, a vítima e o ofensor devem ter o direito à assistência jurídica sobre o processo restaurativo e, quando necessário, tradução e/ou interpretação; crianças e adolescentes devem ter aditivamente a assistência dos pais ou responsáveis legais.

Assim, antes de concordarem em participar do processo restaurativo, as partes devem ser plenamente informadas sobre seus direitos, a natureza do processo e as possíveis consequências de sua decisão, sendo certo que nem a vítima nem o ofensor devem ser coagidos ou induzidos a participar do processo restaurativo ou a aceitar os resultados do processo.

As discussões no procedimento restaurativo não devem ser conduzidas de forma pública; com efeito, a confidencialidade e o sigilo devem ser preservados, exceto se houver expressa e válida autorização das partes.

Os resultados dos acordos oriundos de programas de justiça restaurativa deverão, quando apropriado, ser judicialmente supervisionados ou incorporados às decisões ou julgamentos, de modo a que tenham o mesmo status de qualquer decisão ou julgamento judicial, precluindo ulterior ação penal em relação aos mesmos fatos. 
Quando não houver acordo entre as partes, o caso deverá retornar ao procedimento convencional da justiça criminal e ser decidido $n$ esse âmbito, e com a máxima celeridade possível; ademais, o insucesso do processo restaurativo não poderá, por si, ser evocado no processo criminal subsequente.

A não implementação do acordo feito no processo restaurativo deve ensejar o retorno do caso ao programa restaurativo, ou, ao sistema formal de justiça criminal para que se decida, sem demora, a respeito a não implementação de um acordo extrajudicial não deverá ser usado como justificativa para uma pena mais severa no processo criminal subsequente.

Por sua vez, os mediadores ou facilitadores devem atuar de forma imparcial, com o devido respeito à dignidade das partes. Nessa função, aqueles que dirigem o procedimento devem assegurar o respeito mútuo entre as partes e capacitá-las a encontrar a solução cabível entre elas.

Esses mesmos mediadores ou facilitadores devem ter uma boa compreensão das culturas regionais e das comunidades e, sempre que possível, serem capacitados antes de assumir a função.

\section{JUSTIÇA RESTAURATIVA VERSUS JUSTIÇA RETRIBUTIVA}

O modelo da Justiça Restaurativa está alicerçado numa concepção de consenso, premissa básica em que o ofensor e a vítima, assim como outras pessoas atingidas direta ou reflexamente pela infração penal, participam efetivamente de um processo de produção de alternativas e de soluções objetivando a restauração das perdas e dos traumas advindos da conduta delituosa.

Cuida-se, portanto de um procedimento plasmado pela voluntariedade, caraterizado pela informalidade procedimental, no que se diferencia do modelo tradicional retributivo, em especial pelos seguintes aspectos abaixo assinalados:

\begin{tabular}{|c|c|}
\hline Paradigma Restaurativo & Paradigma Retributivo \\
\hline Paz Social com Dignidade & Paz Social com Tensão \\
\hline $\begin{array}{l}\text { Abordagem do Crime e suas } \\
\text { Consequências }\end{array}$ & Prevenção Geral e Especial \\
\hline $\begin{array}{l}\text { Foco nas relações entre as partes, para } \\
\text { restaurar }\end{array}$ & Foco no infrator para intimidar e punir \\
\hline $\begin{array}{l}\text { Pedido de Desculpas, } \\
\text { Reparação, restituição, prestação e } \\
\text { serviços comunitários. }\end{array}$ & Penalização \\
\hline $\begin{array}{l}\text { Proporcionalidade e Razoabilidade das } \\
\text { Obrigações Assumidas no Acordo } \\
\text { Restaurativo }\end{array}$ & $\begin{array}{l}\text { Penas desarrazoadas e desproporcionais } \\
\text { em regime carcerário desumano, cruel, } \\
\text { degradante e criminógeno; aplicação de } \\
\text { penas alternativas ineficazes }\end{array}$ \\
\hline $\begin{array}{l}\text { Reparação do trauma moral e } \\
\text { dos Prejuízos emocionais - Restauração } \\
\text { e Inclusão }\end{array}$ & $\begin{array}{l}\text { Penas privativas de liberdade, restritivas } \\
\text { de direitos, multa e Estigmatização e } \\
\text { Discriminação }\end{array}$ \\
\hline $\begin{array}{l}\text { Resulta responsabilização espontânea por } \\
\text { parte do infrator }\end{array}$ & $\begin{array}{l}\text { Tutela Penal de Bens e Interesses, com } \\
\text { a Punição do Infrator e Proteção } \\
\text { da Sociedade. }\end{array}$ \\
\hline $\begin{array}{l}\text { Reintegração do Infrator e da Vítima } \\
\text { Prioritárias }\end{array}$ & $\begin{array}{l}\text { Vítima e Infrator isolados, } \\
\text { desamparados e desintegrados. } \\
\text { Ressocialização Secundária }\end{array}$ \\
\hline
\end{tabular}




\section{CONCLUSÃO}

Numa visão meramente perfunctória e prima facie, os postulados da Justiça Restaurativa aparentam estar muito distantes de uma realidade factível e possível, muito em decorrência do fato de que a cultura tradicional dos operadores do direito, durante séculos, foi erigida sobre as bases do enfrentamento do litígio, diante das rígidas formas e modelos ínsitos no sistema retributivo.

Com efeito, a adoção de soluções alternativas de conflito plasmadas por métodos de conciliação e de mediação, se descortina como uma fórmula passível de viabilidade, dotada de grande efetividade e eficiência, até porque as experiências pioneiras e incipientes demonstram a relevância desses sistemas ditos paralelos.

Todavia, para que se possa vislumbrar o emprego dos mecanismos da Justiça Restaurativa em larga escala, necessário se faz que ocorra a quebra do paradigma da infalibilidade do modelo de justiça retributivo representado única e exclusivamente pelo Estado; de outro turno, torna-se imprescindível reconhecer que é possível "realizar justiça" fora das instâncias formais de controle social.

A sociedade contemporânea, demarcada pela urgência e velocidade de suas múltiplas e diversas interações sociais, seja no âmbito das novas formas de famílias que passam a exsurgir, seja no âmbito das multifacetadas relações laborais ou mesmo interpessoais, demanda a perquirição de novos sistemas de gerir e de aplicar a justiça, especialmente se considerarmos estarmos em meio a uma revolução tecnológica que atualiza, a todo instante novas formas de agir e de proceder.

Torna-se imperativo "trocar os óculos" por meio dos quais enxergamos as condutas antissociais, sejam elas criminosas ou não; nessa direção, os postulados do sistema restaurativo alteram o foco do processo penal clássico, buscando ajustá-lo a novas realidades sociais.

A Justiça Restaurativa demonstra ser um modelo adequado às necessidades da sociedade contemporânea, refratária à morosidade de um sistema tradicional e formal, e ansiosa pela concretização dos direitos fundamentais, os quais, muitas das vezes, soam como letra despojada de vida, simplesmente inserta e materializada no corpo da Magna Carta, mas desprovida de efetividade e de eficiência, anseios por demais esperados por uma população cada vez mais sedenta de justiça real e tangível.

\section{REFERÊNCIAS BIBLIOGRÁFICAS}

Acesso à Justiça por Sistemas Alternativos de Solução de Conflitos - Mapeamento Nacional de Programas Públicos e não Governamentais. Ministério da Justiça (Brasil), 2005.

ACHUTTI, Daniel. Modelos contemporâneos de justiça criminal. Porto Alegre: Livraria do Advogado, 2009.

BARATTA, Alessandro. Criminologia crítica e crítica do direito penal: introdução à sociologia do direito penal. Rio de Janeiro: Revan, 2002.

BIANCHINI, Edgar Hrycylo. Capítulo 5 - Princípios da Justiça Restaurativa. Justiça Restaurativa: Desafio à Práxis Jurídica. Campinas: Servanda, 2012.

BRANDÃO, Delano Câncio. Justiça Restaurativa no Brasil: Conceito, críticas e vantagens de um modelo alternativo de resolução de conflitos. Revista âmbito Jurídico, 2014. 
EGLASH, Albert. Beyond Restitution: Creative Restitution. In: Restitution in Criminal Justice”, 1977.

GIACOMOLLI, Nereu José. O processo penal contemporâneo em face do consenso criminal: diálogos corrompidos e persistência no monólogo vertical. In: Gauer, Ruth Maria Chittó (Org.). Criminologia e sistemas jurídico-penais contemporâneos. Porto Alegre: EDIPUCRS, 2008.

JACCOUD, Mylène. Princípios, Tendências e Procedimentos que Cercam a Justiça Restaurativa. In: PINTO, Renato Sócrates Gomes et al. Justiça Restaurativa. Coletânea de Artigos. Brasília: Ministério da Justiça e Programa das Nações Unidas para o Desenvolvimento PNUD, 2005.

PAZ, Silvana. Mediação Penal - Verdade - Justiça Restaurativa. In: Slakmon, C., De Vitto e Renato Sócrates Gomes Pinto (Orgs). Justiça Restaurativa. Brasília-DF: Ministério da Justiça e Programa das Nações Unidas para o Desenvolvimento - PNUD, 2005.

PINTO, Renato Sócrates Gomes. Justiça restaurativa é possível no Brasil? In: Slakmon, C.; De Vitto, R.; Pinto, R. (Orgs.). Justiça restaurativa. Brasília: Ministério da Justiça e Programa das Nações Unidas para o desenvolvimento, 2005.

RESOLUÇÃO 2002/12 da ONU - Princípios básicos para utilização de programas de justiça restaurativa em matéria criminal.

SHEARING, Clifford e Froestad, Jan. Prática da Justiça - O Modelo Zwelethemba de Resolução de Conflitos. In: Justiça Restaurativa. Ministério da Justiça, Brasil, 2005.

SICA, Leonardo. Bases para o modelo brasileiro de Justiça Restaurativa. Revista Jurídica do Ministério Público do Estado de Minas Gerais, Belo Horizonte, n. 12, 2009.

Justiça Restaurativa e Mediação Penal. O Novo Modelo de Justiça Criminal e de Gestão do Crime. Rio de Janeiro. Editora Lumen Juris, 2007.

SILVA, Karine Duarte Rocha da. Justiça Restaurativa e sua aplicação no Brasil. Brasília, 2007.

SOUSA, Aziel Henrique de. Justiça Restaurativa: O que é e como funciona. Brasília: CNJ, Conselho Nacional de Justiça. 2014.

ROLIM, Marcos; SCURO NETO, Pedro; DE VITTO, Renato Campos Pinto e PINTO, Renato Sócrates Gomes. Justiça Restaurativa - Um Direitos Humanos? Caminho para os Textos para Debates, Ed. IAJ - Instituto de Acesso à Justiça, Porto Alegre, 2004.

TJSP usa Justiça Restaurativa na ressocialização de jovens. CNJ, $1^{\circ}$ de janeiro de 2013. 